\title{
A LABUTA SEM CIRANDA: CRIANÇAS POBRES E TRABALHO EM MARIANA (1850-1900)
}

\author{
Labour without pleasantry: poor children and \\ work in Mariana (1850-1900)
}

Heloísa Maria Teixeira*

\section{RESUMO}

Nosso objetivo, nesse texto, consiste em investigar o interesse pela utilização da criança como mão-de-obra nas propriedades da localidade de Mariana na segunda metade do século XIX. Mariana, desde o declínio da mineração, passou a ter como atividade econômica principal a produção de alimentos, tanto para subsistência quanto para o abastecimento do mercado inter e intraprovincial. O período em foco consiste em um momento de transição do sistema escravista para o sistema livre de trabalho. Naquele momento, acirraram-se as discussões sobre como dar-se-ia a transição. Entre as alternativas em debate, estava aquela que idealizava o emprego da mão-de-obra nacional em substituição à escrava. Nesse contexto, as crianças, que poderiam ser educadas desde cedo para o trabalho, eram especialmente interessantes, pois apresentavam maior facilidade de subjugação (jornadas de trabalho estafantes, remuneração ínfima ou inexistente, castigos, etc.), além de perspectiva de vida longa. Os fatores que inserem a criança no mundo do trabalho estão ligados à orfandade e às dificuldades de sobrevivência que, amiúde, resultavam na necessidade de os filhos de famílias pobres enfrentarem a lida diária ou até mesmo partirem para outros domić́lios em busca de trabalho, a fim de contribuir ou mesmo manter a subsistência da família. Trabalharemos com registros de tutela, remoções de tutela, processos-crime e o recenseamento de 1872.

Palavras-chave: transição para o trabalho livre; economia de subsistência; trabalho infantil.

" Mestre em História Econômica pela Universidade de São Paulo, Doutoranda em História econômica pela Universidade de São Paulo. 


\begin{abstract}
Our intent for this paper consists in a investigation over the interest for the use of children as labourers in the properties of Mariana in the second half of $19^{\text {th }}$ century. Since the decline of mining, Mariana concentrated on food production as its main economic activity, both for subsistence or to supply its own province and export to others. The focused period constitutes a transition from the slavery system to free labor one. At that time, the argumentation about how the transition would be made was incited. One of the alternatives idealized national free labour as a substitute for slave labour. In these circumstances, the little workers could represent a feasible alternative, therefore they offered easier subjugation conditions (fatiguing labor journeys, lowermost or no remuneration at all, punishments, etc.), besides a long life perspective. The factors that introduce children into the labor world are associated to orfanhood and survival difficulties, which often forced the children from poor families to face daily toil or even to leave in search of work in strange houses, in order to contribute or even support their own families. We will consult tutelage records, tutelage transfers, criminal suits and the 1872 census.
\end{abstract}

Key-words: transition from the slavery system to free labor one; subsistence economy; child labor.

\title{
Considerações iniciais
}

A segunda metade do século XIX foi um momento de transição do sistema escravista para o sistema livre de trabalho. A cessação do tráfico internacional de escravos (em 1850), a liberdade concedida às crianças nascidas de mães escravas (1871) e aos escravos com mais de 60 anos (1885) e a Lei de Locação de Serviços (1879) foram acontecimentos inseridos nesse processo de transição, que ocorreu de forma gradativa, cujo corolário foi a abolição da escravatura. De 1850 a 1871, os senhores tinham no tráfico interno e na reprodução natural a esperança de perpetuação do regime, mas, depois da Lei Rio Branco, a segunda possibilidade foi "teoricamente" eliminada pelo ventre livre das escravas. Tal lei, entretanto, permitia aos escravistas a utilização da mão-de-obra dos ingênuos até que estes completassem 21 anos. Além desta possibilidade, os senhores ainda podiam optar 
pela compra de escravos no mercado interno ou mesmo pela contratação de trabalhadores assalariados. O senhor que desejou manter a utilização da mão-de-obra compulsória teve algumas dificuldades. A maior delas talvez tenha sido a elevação dos preços dos cativos ocorrida nesse período.

Neste contexto, acirravam-se as discussões sobre a transição do sistema escravista para o de trabalho livre. Entre os projetos, estava aquele defendido pelos lavradores de Minas Gerais, Rio de Janeiro, Espírito Santo e os paulistas representantes do Vale do Paraíba, que idealizava o emprego da mão-de-obra nacional. Pretendia-se, assim, incorporar livres pobres, libertos e ingênuos como força de trabalho ${ }^{1}$. Durante o processo abolicionista, a posição do negro nessa nova ordem sempre foi discutida e refletida. A questão era assegurar a força de trabalho das categorias mencionadas, especialmente das crianças, que poderiam ser educadas desde cedo para o trabalho.

Por ora, entraremos na discussão debruçando nossos olhares sobre a criança ${ }^{2}$ livre pobre. Aqueles com pouca idade foram parcamente citados pelas fontes do passado. Se pouco se registrou acerca da vida diária e dos aspectos mais corriqueiros do cotidiano infantil do Brasil pretérito, menos ainda foi registrado sobre o trabalho infantil. Na ausência de um corpus específico, partimos para uma "garimpagem documental", a fim de obter informações que nos revelassem a criança sem posses no mundo do trabalho da Mariana oitocentista. Guiaram-nos nessa empreitada os processos de tutela, os criminais e o recenseamento de 1872.

\section{As crianças na população marianense}

Para as localidades mineiras da segunda metade do século XIX, a ausência - ou o desconhecimento - de fontes regionais que retratem o contingente populacional da província faz do recenseamento nacional de 1872 (realizado em Minas Gerais em 1873) a fonte largamente utilizada entre

1 Ver GEBARA, 1986; KOWARICK, 1987; LANNA, 1989.

2 Trabalharemos com a faixa etária 0-14 anos. 
as pesquisas que visam a analisar a população mineira daquele período. Nesse recenseamento, a população marianense foi contabilizada em 42.424 almas - sendo 34.002 livres e 8.422 escravos $^{3}$. Entre a população total, 10.275 $(24,2 \%)$ eram crianças. Destas, 8.784 eram livres e 1.491 , cativas.

TABELA 1 - População total e de crianças segundo gênero e condição - Mariana, 1873

\begin{tabular}{|l|c|c|c|c|c|}
\hline \multirow{2}{*}{ Gênero/Condição } & \multirow{2}{*}{ População total } & \multicolumn{4}{|c|}{ Crianças (0-15 anos) } \\
\cline { 3 - 4 } & & $n$ & $\%$ & $N$ & $\%$ \\
\hline Masculino/Livre & 17.282 & 4.520 & 26,2 & \multirow{2}{*}{8.784} & 25,8 \\
\hline Feminino/Livre & 16.720 & 4.264 & 25,5 & & \\
\hline Masculino/Escrava & 4.644 & 816 & 17,6 & \multirow{2}{*}{1.491} & 17,7 \\
\hline Feminino/Escrava & 3.778 & 675 & 17,9 & & \\
\hline Total & $\mathbf{4 2 . 4 2 4}$ & $\mathbf{1 0 . 2 7 5}$ & $\mathbf{2 4 , 2 \%}$ & $\mathbf{1 0 . 2 7 5}$ & $\mathbf{2 4 , 2}$ \\
\hline
\end{tabular}

FONTE: Recenseamento nacional de 1872

Em relação ao conjunto da população, as crianças livres ocupavam proporção maior que as escravas (Tabela 1). As explicações para essa diferença podem ser: menor índice de natalidade e maior índice de mortalidade para a população escrava em relação à livre, alforrias, ventre livre das escravas $^{4}$. Entretanto, não constitui nosso objetivo discuti-las. $\mathrm{O}$ fato de a maioria das crianças estarem na condição de livre não significa necessariamente uma posição privilegiada ante os infantes escravos. Segundo Maria Luiza Marcílio, "excluída uma minoria, que certamente mal chegaria aos 10\% de toda a população infantil brasileira, em todas as regiões e épocas de nossa História, a quase totalidade de nossas crianças pertencia às categorias menos favorecidas de nossa sociedade" ${ }^{5}$.

3 Um ofício do governo provincial, datado de 28 de novembro de 1854 , requereu mapas das populações livre e escrava de freguesias e termos mineiros. As freguesias do termo de Mariana responderam ao ofício em 1855 e 1856. Alguns mapas desse período já foram "descobertos" nos arquivos marianenses, mas ainda não abrangem o município como um todo. Assim que coletadas todas as listas referentes à localidade em questão, serão agregadas às fontes de nossa pesquisa.

4 O recenseamento na província mineira, efetivamente, ocorreu em agosto de 1873 . Sendo a Lei Rio Branco promulgada em setembro de 1871, mesmo que em pequena escala, certamente teve influências nessa estatística.

5 MARCÍLIO, 1992, p. 4. 
A relação entre os sexos era equilibrada entre as crianças livres: índice de masculinidade igual a 106. Já para as crianças escravas, a relação entre os sexos denotava vantagem demográfica masculina: índice de masculinidade igual a 121. Tais índices são próximos dos calculados para a população total que eram, para a população livre, de 103, e, para a população escrava, de 123.

\section{Criança e trabalho: vestígios da relação}

De maioria pobre, as crianças encaravam o trabalho desde tenra idade para garantir a própria sobrevivência ou de suas famílias. Os fatores que inseriam a criança no mundo do trabalho estavam ligados à orfandade $\mathrm{e}$ às dificuldades de sobrevivência familiar, que, amiúde, resultavam na necessidade de os filhos enfrentarem a lida diária tal como seus pais e irmãos ou até mesmo partirem para outros domicílios em busca de trabalho.

Dentro dos limites da vivência familiar, o trabalho infantil ocorria com regularidade, estando a criança, desde cedo, responsável por atividades ligadas ao grupo familiar. Maria Sílvia Bassanezi e Ana Sílvia Scott observaram as seguintes tarefas para as crianças filhas de imigrantes italianos nas fazendas paulistas de fins do século XIX e início do XX:

Cuidar dos irmãos menores, ajudar nos serviços da casa (tarefas delegadas principalmente às meninas), levar comida para a roça, cuidar das hortas e tratar animais, participar da colheita do café e ajudar na lavoura de subsistência (...). A importância deles, para a sobrevivência da família, repousava no fato de que ajudavam a reduzir o trabalho da mãe, ou de outra mulher, nos serviços da casa e porque, junto com ela, no trabalho do café e das culturas auxiliares, contribuíam para aumentar os ganhos da família. (...). O cotidiano de trabalho para a criança e o jovem, que viviam na pequena propriedade rural, não diferia muito daquele observado na fazenda de café; estavam submetidos a tarefas semelhantes. Aí também a sobrevivência 
do grupo e a possibilidade de poupança familiar dependiam da intensidade do trabalho de todos os elementos aptos da família. ${ }^{6}$

Muitas vezes, o caminho trilhado pelas crianças desprovidas ultrapassava as barreiras da convivência familiar, sendo as mesmas "acolhidas" por outras famílias, em geral mais abastadas. As razões para essa transferência podiam ser consequiências diretas das condições familiares - pobreza, falta de "autoridade moral" - ou da orfandade. Nesses casos, o papel ocupado pelas crianças nos domicílios acolhedores sempre estava associado à prestação de serviços. O funcionamento do sistema de "acolhida" girava em torno da troca. O domicílio acolhedor fornecia proteção, subsistência e educação e o acolhido pagava com tarefas, serviços ou trabalhos.

O sistema poderia ser legitimado pelo Juízo de Órfãos por meio da tutela. O vínculo da tutela era estabelecido a partir do momento em que o juiz nomeava um tutor para uma criança. Ao tutor, cabia a função de educar os tutelados como pessoas livres, conduzi-los ao aprendizado de uma profissão, além de ensiná-los a ler e escrever. O objetivo era permitir que, no futuro, tais menores pudessem adquirir meios de subsistência adequados para sua sobrevivência e de sua futura família. Normalmente, os candidatos a tutor eram chamados pelos juízes a "justificar", isto é, provar que se tratavam de pessoas idôneas para desempenhar funções de tutela.

A coleta dos registros de tutela para a localidade focada em nossa pesquisa está ocorrendo de forma não ordenada e bastante lenta, pois, no arquivo onde estão guardados (Arquivo da Casa Setecentista de Mariana), os documentos referentes ao Juízo de Órfãos ainda não foram catalogados, fazendo parte de um grande volume documental ainda não identificado ${ }^{7}$. Dessa forma, chegar até eles envolve a abertura de caixa por caixa de um arquivo que guarda cerca de 300 anos de documentação cartorial. À medida que esses processos são coletados, registramo-los em pastas identificadas como "Juízo de Órfãos".

Até o momento, coletamos 27 processos de tutela referentes a crianças pobres. No total, esses processos envolveram 37 crianças. A pequena

6 BASSANEZI; SCOTT, 2003, p. 7.

7 Parte substancial da documentação referente ao Juízo de Órfãos ainda se encontra armazenada no Fórum da cidade de Mariana e será também levantada no decorrer da pesquisa. 
amostragem limitará nossas conclusões quantitativas, mas sua análise qualitativa permitir-nos-á conhecer os fatores que conduziram os menores à categoria de tutelados.

TABELA 2 - Crianças tuteladas, segundo gênero, cor e filiação - Mariana, segunda metade do século XIX

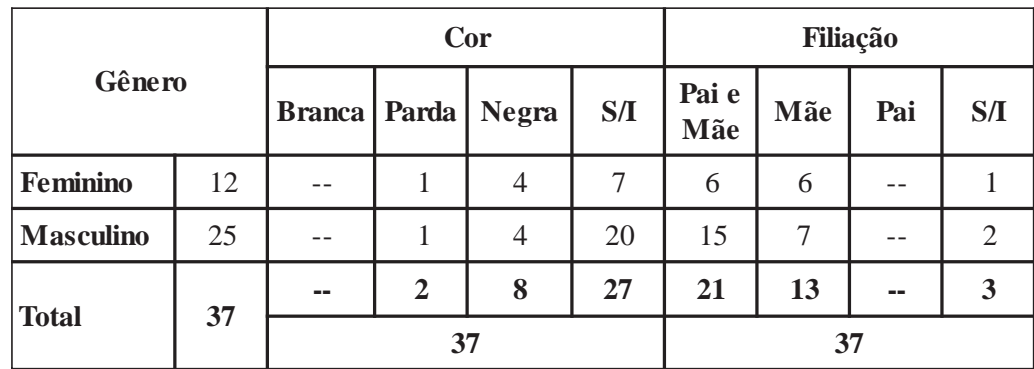

S/I - Sem informação

Os meninos eram maioria: o dobro do número de meninas entre os menores tutelados (Tabela 2). A cor poucas vezes foi revelada. As idades dos tutelados, embora não estejam explicitadas na tabela, ajudam-nos a pensar sobre a instituição da tutela ${ }^{8}$. Apenas dois tutelados estavam na faixa etária 0-5 anos - uma menina de 4 e um menino de 5 anos. Outros 21 estavam com idades que variavam entre 6 e 14 anos ( 11 deles, entre 10 e 14 anos). A idade de 14 tutelados não foi descrita, sendo reconhecidos como crianças (0-14 anos) pelas qualificações menino, menor, de pouca idade, etc. Nossa pequena amostragem torna qualquer conclusão precipitada nesse momento, mas podemos especular que crianças muito pequenas seriam um transtorno para as famílias tutoras pelos cuidados que exigiam. As crianças com idade mais avançada, além de já criadas, poderiam rapidamente ser introduzidas em serviços nos domicílios receptores. Nesse sentido, o sexo dos infantes também deveria ter relações com a produtividade: meninos teriam a preferência, principalmente nos domicílios envolvidos com lavoura e criação de animais.

8 No prosseguimento deste trabalho, pretendemos dividir nossa amostragem segundo faixas etárias. Neste momento, consideramos que tal divisão não será necessária, devido ao pequeno número de tutelados. 
A Tabela 2 relaciona, também, a filiação das crianças tuteladas. Em 21 casos, a descrição da filiação abrangeu pai e mãe e, em 13 situações, apenas a mãe foi descrita. Para três casos, a filiação era desconhecida e crianças com a descrição apenas do pai não constaram da amostragem. O fato de a maioria das crianças ter a filiação descrita chama a atenção justamente por tratar-se de processos que, mormente, transferem para outrem a responsabilidade de proteção aos petizes. Na verdade, a especificação da filiação não desmente a condição de órfão na qual viviam muitas das crianças tuteladas.

TABELA 3 - Situação familiar das crianças tuteladas - Mariana, segunda metade do século XIX

\begin{tabular}{|l|c|c|c|c|c|c|}
\hline $\begin{array}{c}\text { Filiação } \\
\text { Descrita }\end{array}$ & Total & $\begin{array}{c}\text { Pai e mãe } \\
\text { vivos }\end{array}$ & $\begin{array}{c}\text { Mãe } \\
\text { viva }\end{array}$ & $\begin{array}{c}\text { Pai e mãe } \\
\text { falecidos } \\
\text { (Órfão) }\end{array}$ & $\begin{array}{c}\text { Órfão de } \\
\text { mãe }\end{array}$ & $\begin{array}{c}\text { Órfão de } \\
\text { Pai }\end{array}$ \\
\hline Pai e mãe & $\mathbf{2 1}$ & 1 & -- & 7 & 4 & 9 \\
\hline Mãe & $\mathbf{1 3}$ & -- & 6 & -- & 7 & -- \\
\hline
\end{tabular}

Das 21 crianças que tiveram paternidade e maternidade descritas, apenas em um caso pai e mãe estavam vivos (Tabela 3). Em sete casos, as crianças tiveram pais e mães descritos como falecidos. Em quatro processos, apenas as mães estavam falecidas e, em nove casos, eram os pais que estavam mortos. As crianças que tiveram a descrição apenas das mães as tinham presentes em seis situações e, em sete, eram órfãs das mesmas.

Mesmo que a tutela não fosse estabelecida apenas nos casos em que a criança não possuísse genitores - veremos que, em muitos casos, os pais não possuíam condições de cuidar de seus filhos -, a orfandade ${ }^{9}$ era a justificativa principal dos processos de tutela. Este argumento foi usado na tutela de Felipe, de aproximadamente 10 anos, órfão de Francisca, ex-escrava do tenente Manuel Basílio do Espírito Santo, também falecido.

O menor Felipe, desamparado como se acha em uma idade que precisa de educação, ficará sem dúvida inutilizado se lhe faltar

9 Consideramos casos nos quais a criança tenha perdido todos os genitores conhecidos (pai e mãe ou apenas mãe). 


\begin{abstract}
agora o patrocínio do Juiz de Órfãos, dando-lhe um tutor que lhe dirija para ser no futuro um cidadão útil. Não tem ele parentes no caso para lhe prestar uma educação conveniente, tendo entretanto um padrinho que é o reverendo senhor cônego José Caetano de Faria, que não nega de aceitar a tutela do menor Felipe. ${ }^{10}$
\end{abstract}

Nessa situação, o juiz concedeu, em 17 de fevereiro de 1893, a tutela do menor para o reverendo, que se encarregou de cuidar de sua educação, promovendo seus direitos tanto em juízo quanto fora dele como se fosse seu verdadeiro pai. $\mathrm{O}$ fato de o tutor ser um clérigo não o redime de possíveis intenções que vinculassem Felipe à prestação de serviços. Sua condição de proprietário de terras e a preocupação em tornar o menor um “cidadão útil" (o que englobaria ensinar-lhe uma profissão) insinuam que o jovem pagaria com trabalho sua permanência na propriedade.

O garoto José, com idade entre 10 e 12 anos, também era um órfão desamparado que, em 1878, comoveu o cidadão Cipriano Vieira Marques. Este, em juízo, foi anunciar

que no quarteirão de seu domicílio (...) vagueia uma criança de sexo masculino, de nome José, de 10 para 12 anos de idade, filho natural e órfão de Maria (...), destituído de toda a proteção porque os mais próximos parentes, além de muito indigentes, são incapazes de educá-lo pelo estado de imoralidade e desregramento em que vivem, e, doendo ao suplicante o deplorável estado desta criança que permanece em completo abandono, só tendo diante dos olhos o exemplo de degradação e de vícios que são comuns na sociedade em que vive, vem por isso apresentar e pedir a proteção de Vossa Senhoria (...) desse desvalido, dando-lhe o possível e legal apoio da Lei e da Justiça. ${ }^{11}$

O que pensar desta declaração? Seria verdadeira? Cipriano sensibilizou-se realmente com a situação do jovem José ou desejava mais do que proteger o menino abandonado? A historiografia já revelou que muitos arti-

10 Arquivo da Casa Setecentista de Mariana, Processos Avulsos, códice 20, auto 418 11 Arquivo da Casa Setecentista de Mariana, Processos Avulsos, códice 3, auto 36. 
fícios foram usados pelos candidatos a tutores com o propósito de convencer a justiça da importância da tutela para a formação dos menores ${ }^{12}$. Entre os artifícios estão o abandono e a falta de condições das famílias pobres descritas sempre como viciosas - em educar seus filhos. Estranha-se que, apenas quando José atingiu certa idade, Cipriano enxergou-o como destituído de toda a proteção e prontificou-se a ajudá-lo. A citação acima também chama a atenção para o fato de que, apesar de José possuir parentes, estes eram incapazes de oferecer a educação devida ao menor: os mais próximos parentes, além de muito indigentes, são incapazes de educá-lo pelo estado de imoralidade e desregramento em que vivem. Tal afirmação seria real ou uma estratégia de convencimento aplicada em Juízo? Diante das informações prestadas sobre os familiares de José e da idoneidade do cidadão Cipriano, a tutela foi concedida pouco tempo depois do início do processo.

Também foi a preocupação com o futuro que conduziu o capitão Antônio Vicente Ferreira de Oliveira ao juiz de órfãos para relatar a situação de Carolina, de mais ou menos 10 anos, que, em setembro de 1888, acabava de perder seu padrinho, Manuel Caetano de Faria. Nesse momento, a pequena Carolina já era órfã de pai e mãe, sendo cuidada pelo padrinho e sua mulher, dona Leocádia. Diante da circunstância, a alegação do suplicante, o capitão Antônio Vicente Ferreira de Oliveira, foi a de que dona Leocádia, em cuja companhia a menor Carolina deveria permanecer, não poderia continuar a cuidar da menina

visto [esta] estar em uma idade que precisa de quem lhe dispense cuidados que não poderão ser dispensados por dona Leocádia, que é senhora doente e que não pode ser sobrecarregada de cuidados e trabalho. Nestas condições, venho propor me candidatar a tutor da referida órfã Carolina. ${ }^{13}$

O juizado aceitou os argumentos do dito capitão, que passou a ser o tutor da órfã Carolina. Essa história remete-nos à condição de inferiorida-

12 AZEVEDO, 1995; ALANIZ, 1997; PAPALI, 2003

13 Arquivo da Casa Setecentista de Mariana, I Ofício, Processos Avulsos, códice 20, auto 412. 
de na qual estava inserida a mulher, considerada menos capaz de realizar os cuidados necessários à guarda de uma criança. Condição que justificou alguns processos de tutelas. Entre eles, estava o pedido de tutela do menino José, de 8 anos, filho legítimo de Antônia Francelina e seu finado marido (falecido havia 4 anos, mais ou menos), pelo cidadão Joaquim Martins da Silva, feito em 1895. Durante o processo, ficou claro que José já vivia em companhia de Joaquim havia algum tempo, o que provaria sua capacidade para tutelar o menino. O pedido de tutela foi feito sem apresentar nenhum argumento que explicitasse a incapacidade da mãe de José ou a desqualificasse.

O cidadão Joaquim Martins da Silva é idôneo e capaz de bem desempenhar, tanto que já tem em sua companhia o referido órfão que o zela como verdadeiro pai, sendo certo que na Passagem [onde tutor e a mãe de José residem] não tem o órfão parente idôneo que possa ser nomeado tutor. ${ }^{14}$

Em situação ainda pior deveriam estar as mulheres descendentes da escravidão ${ }^{15}$. Foi registrado, no ano de 1888 , o pedido de tutela feito pelo cidadão Clemente Gomes da Cunha das menores Maria e Fé, de 10 e 8 anos, filhas de Joana, ex-escrava do dito Clemente. O senhor Clemente relata que as menores

têm sido criadas no seio da família do suplicante que é bem conhecido para dispensar prova da capacidade para prover os meios de educação e estabelecimento das mesmas, além dos sentimentos que o princípio da criação liga ao coração, acresce a presunção de prenderem-se as mesmas menores ao suplicante

14 Arquivo da Casa Setecentista de Mariana, I Ofício, Processos Avulsos, códice 9, auto 214 15 "A justiça considerava a mulher solteira e pobre inapta para a criação dos filhos menores" (PAPALI, 2003, p. 184). "Mães 'solteiras pobres', libertas ou sem recursos mesclavam-se num único enunciado que parecia conter todas as informações necessárias, dispensando maiores argumentações, ou seja, tais mães não estariam nos 'casos de serem tutoras', não teriam recursos para criar e educar seus filhos. Muitas vezes, apenas a indicação de liberta, preta, parda ou 'Maria de Tal' parecia conter todos esses preceitos preconcebidos em relação a essas mulheres" (PAPALI, 2003, p. 155). 
por laço de consangüinidade como descendentes do seu tronco no grau de netas. ${ }^{16}$

Também nesse caso a superioridade do candidato a tutor não foi questionada. Vejamos o que diz o Juízo de Órfãos:

\begin{abstract}
Não precisa o suplicante demonstrar a superioridade dos meios que dispõe em relação à mãe das mesmas, bastando a condição de onde ela saiu para determinar a diferença no modo de compreender os deveres sociais. (...) Nessa condição não tenho que me opor, visto conhecer a idoneidade do tutor que se pretende dar às menores Maria e Fé. ${ }^{17}$
\end{abstract}

A falta de recursos econômicos levou famílias pobres a procurar tutores para sua prole como uma garantia de sobrevivência. Entre as mulheres, a morte dos companheiros poderia conduzir a essa opção. Foi a dificuldade de criar seus sete filhos - Flávio Quintino, Ilídio Quintino, Dirceu Quintino, Antônio Quintino, Elisa, Jovita e Maria -, todos menores e frutos da união com o falecido Francisco Quintino, que levou Maria José dos Santos a requerer-lhes um tutor.

O segundo casamento da senhora Maria José, com Eliseu Teodoro Gomes, deu-lhe e a seus rebentos uma residência, a fazenda do Batieiro, onde Eliseu trabalhava. Isso, porém, não era suficiente e, em 1889, Maria José afirmou, em Juízo, que sua condição e classe social não permitiam que nem ela nem seu segundo marido possuíssem recursos para educar e dar instrução compatível a seus filhos e que, por isso, requeria nomear-lhes um tutor, 
senão os impulsos do seu generoso coração, pois os menores são órfãos desvalidos e seus pais destituídos de recursos. ${ }^{18}$

Para o proprietário da fazenda deve ter sido um ótimo negócio, pois poderia utilizar os menores na lida sem compromissos financeiros, já que a lei não obrigava pagamento aos menores de 14 anos.

\begin{abstract}
A partir dos 14 anos, era obrigatório pagar soldo a todos os assoldados. No entanto, dos 7 aos 14 anos, a decisão das crianças assoldadas receberem algum dinheiro dependia dos juizes de órfãos. Estabelecia a legislação: "o Juiz dos Órfãos, quando julgar conveniente, poderá autorizar estas locações de serviços, não vencendo os menores soldada até a idade de quatorze anos, e obrigando-se simplesmente os amos á alimentá-los, vesti-los e tratá-los nas enfermidades". "Quem tiver criado órfãos até a idade de sete anos, e continuar á tê-los em sua companhia, não pode ser obrigado á pagar-lhes soldadas por serviços prestados até a idade de 14 anos. Também não tem obrigação de pagar soldada os tutores ou mães dos órfãos que os conservarem em sua companhia, e se utilizarem de seus serviços, por lhes não poderem dar arrumação". ${ }^{19}$
\end{abstract}

A dificuldade financeira foi a provável causa pela qual o pai de Sérgio, natural do distrito de Vermelho Velho, de termo de Ponte Nova, entregara-o para o cidadão João de Mello, residente no distrito marianense de São Sebastião. Falecendo João de Mello em 1896, Sérgio, com aproximadamente 12 anos, viu-se abandonado, "entregue a si mesmo e, por isso, no caminho de perder-se se não tiver quem lhe dirija na sua inexperiência" ${ }^{20}$. Como seu pai ainda vivia, o juiz de órfãos tomou a medida de depositá-lo à pessoa competente que lhe desse ocupação até que o pai o reclamasse.

A denúncia foi feita por José Caetano Aleixo, que requereu o depósito de Sérgio, comprometendo-se a fornecer-lhe uma ocupação. Em troca

18 Arquivo da Casa Setecentista de Mariana, I Ofício, códice 476, auto 10.605. 19 FREITAS, A. T. Esboço do Código Civil. Artigo 2.710, p. 1.014 apud AZEVEDO, 1995, p. $80-81$

20 Arquivo da Casa Setecentista de Mariana, I Ofício, Processos Avulsos, códice 8, auto 106 
dos serviços prestados, Sérgio seria recompensado com o pagamento de uma soldada de 15 mil réis mensais (sendo descontados 5 mil réis mensais para vestuário). Ao tutor, cabia ainda promover o aprendizado educacional do menor, ensinando-o a ler e escrever, assim como o aprendizado de uma profissão consoante com sua inclinação. Prometeu ainda que, findo o tempo de três anos, se comprometia a elevar a soldada de seu depositado conforme merecimento. Diante dos compromissos assumidos, o juiz determinou:

\begin{abstract}
para depositário o cidadão José Caetano Aleixo que se acha residindo em São Sebastião o qual se propõe pagar ao menor uma mensalidade, (...) sendo como me parece de grande vantagem para o menor, que vai ter quem cuide de sua pessoa e que ainda o remunere pelos seus serviços. ${ }^{21}$
\end{abstract}

Três anos depois, José Caetano Aleixo pediu exoneração do cargo de depositário, alegando ter de se mudar para fora da comarca. O depósito do menor Sérgio transferiu-se para o cidadão doutor Manuel Faustino Correa Brandão, "que conhece o menor que reside ao pé do seu domicílio para servir de depositário, visto como verem em si as qualidades de um verdadeiro patrono, pai de família exemplar que, além de garantir a soldada, ainda pode auxiliar a educação do menor em qualquer profissão que deva servir". ${ }^{22}$ Mesmo não havendo aumento do valor da soldada - que continuava correspondendo a 15 mil réis mensais (descontados 5 mil réis para vestuário) -, o novo depositário reclama que a quantia de 5 mil réis é insuficiente para manter o vestuário do jovem devido ao preço exagerado das vestes. Por isso, pede elevação desse valor para 10 mil réis, no que foi atendido pelo juiz, passando o valor efetivo dos serviços prestados por Sérgio para 5 mil réis ${ }^{23}$.

A soldada era depositada no cofre dos órfãos e só poderia ser retirada quando o jovem se emancipasse, o que ocorria pelo casamento ou

\footnotetext{
21 Arquivo da Casa Setecentista de Mariana, I Ofício, Processos Avulsos, códice 8, auto 106 22 Arquivo da Casa Setecentista de Mariana, I Ofício, Processos Avulsos, códice 8, auto 106, p. 6 v e p. 7.

23 Valor que permanecerá inalterado até 1904, quando, através do casamento, Sérgio consegue sua emancipação.
} 
pela maioridade (aos 21 anos). À vista disso, muitos tutores deixavam de cumprir seus deveres. Burlando as leis, usufruíam do trabalho infantil e, ao serem convocados para prestar as devidas contas, alegavam inúmeros motivos para escapar do pagamento do soldo. Nos casos em que a soldada não era depositada, cabia à justiça requerer a efetuação do direito. Tal intervenção teve que ser feita para garantir o depósito da soldada em nome do menor Sérgio.

Requeiro que o tutor faça recolher ao cofre as mensalidades em seu poder referentes aos meses de abril a setembro do corrente ano [1897]. (...) Feita a conta, seja intimado o depositário e responsável pelo menor para no prazo de nove dias entrar com o líquido a que tiver direito o menor. ${ }^{24}$

O pagamento de soldadas aos tutelados evidencia o interesse por sua mão-de-obra, pois a soldada seria paga mediante prestação de serviços aos tutores. $\mathrm{O}$ caso do menino Sérgio deixa claro que o interesse era apenas no trabalho a baixo custo que poderia prestar aos seus tutores. As obrigações que deveriam ter com o menor parecem ter sido negligenciadas, pois, quando de sua emancipação, no ano de 1905, ele menciona não saber ler nem escrever e nem ter profissão definida.

Muitas vezes, a tutela funcionava como um mecanismo de reforço a uma situação que poderia ser alterada com a rebeldia dos jovens quando crescidos. Josias tinha apenas três anos quando passou para os cuidados do senhor José Gomes de Almeida Costa no ano de 1887. Somente oito anos mais tarde, houve a preocupação do senhor José Gomes em formalizar a tutela. A razão para tal atitude pode ser conhecida no trecho abaixo.

Diz José Gomes de Almeida Costa, residente no Infeccionado [freguesia de Mariana] desta comarca, que, tendo ele suplicante tomado desde a idade de 3 anos o menor Josias, filho sem mãe nem pai conhecidos, para criá-lo e educá-lo, o qual está com a idade atualmente de 11 anos incompleta, temendo, porém, o

p. 11v.

24 Arquivo da Casa Setecentista de Mariana, I Ofício, Processos Avulsos, códice 8, auto 106, 


\begin{abstract}
suplicante, que alguém seduza-o feito já estar em circunstância de prestar algum serviço, desviando-o da educação moral e religiosa que lhe tem dado o suplicante, e tire-o do ensino das primeiras letras que está completando em escola pública por todos estes anos, vem requerer vossa excelentíssima se digne nomear o suplicante seu tutor. ${ }^{25}$
\end{abstract}

Esse fragmento revela o receio de José Gomes de Almeida Costa em perder todo o investimento aplicado na criação e educação de Josias, exatamente quando começaria a prestar-lhe algum serviço. Comprova ainda a prática - que parece comum - de usufruto dos menores desvalidos como mão-de-obra: José Gomes afirmou temer que o menor encontrasse alguém que o seduzisse, feito já estar em circunstância de prestar algum serviço.

A situação de exploração que muitas crianças viviam nos domicílios dos tutores, quando conhecidas pelos parentes, eram causa de pedidos de remoção da tutela. O processo seguinte trata de um pai, Philomeno Martins Quintão, que tentava obter a tutela dos filhos.

Era o ano de 1881 e o processo começou com Philomeno Quintão afirmando que, "por fragilidade sua", teve três filhos ingênuos com a escrava Maria crioula: Jerônimo, com 5 anos; Inês, com 4 anos; e Maria, falecida antes de completar o primeiro ano de vida. Maria crioula, antes pertencente à dona Isabel Maria de Jesus Gomes (irmã de Philomeno), foi vendida ao senhor Joaquim Quintão (também irmão de Philomeno) que, por sua vez, vendeu-a a Manuel Machado Moniz em 1878.

Nessa ocasião, não procurou Machado saber se a escrava Maria tinha filhos livres e, antes levando um deles com idade de 11 meses, fez apartar criança e mãe e ficando [a criança] entregue na fazenda dos Quintão veio a falecer, talvez por ser desmamada antes do tempo. ${ }^{26}$

Jerônimo ficou com o pai e Inês com o cidadão Luís Coelho. O menino foi transferido para a guarda do fazendeiro Silvério dos Santos Vellozo

25 Arquivo da Casa Setecentista de Mariana, I Ofício, códice 8, auto 112.

26. Arquivo da Casa Setecentista de Mariana, I Ofício, códice 389, auto 8.498 . 
depois de este prometer a Philomeno que cuidaria de sua criação e educação. Entretanto, o Senhor Manuel Machado, proprietário de Maria crioula, mãe de Jerônimo, aproveitando-se da ausência de Silvério Vellozo, tirou-lhe o poder sobre o ingênuo, o qual levou para sua companhia. Segundo o pai, Philomeno Quintão,

\begin{abstract}
(...) este procedimento de Machado, outro fim não atinge senão gozar dos serviços do menino até a idade dos 21 anos, quando pára de ter direito. $\mathrm{A}$ isto era necessário que ele o tivesse criado ao lado de sua mãe, e não agora que o dito menor já conta de 5 anos e mais de dois separado de sua mãe e que tem o suplicante como pai para velar por ele. O suplicante prevê que Machado, um velho analfabeto e que já foi bárbaro e desumano com a infanta Maria, irmã de Jerônimo, não pode ser benfeitor deste. Nestas circunstâncias, pois bem o suplicante requer a Vossa Senhoria para que lhe seja entregue o menor Jerônimo a que se refere, obrigando-o o suplicante a acabar de criá-lo e fazê-lo o benefício que couber em suas forças (...). ${ }^{27}$
\end{abstract}

Mesmo transferindo a terceiros a obrigação de cuidar dos menores, Philomeno Quintão recebeu o direito de tutelar não só Jerônimo, mas também a menor Inês. A indignação manifestada por Philomeno ao saber que seu filho Jerônimo estava em mãos do senhor Manuel Machado Moniz suscita o seguinte questionamento: seria diferente o interesse dos tutores Silvério dos Santos Vellozo e Luís Coelho na guarda dos menores?

O sentimento de revolta podia acontecer com o próprio menor. Foi tentando pôr fim aos maus tratos que sofria que Antero, no ano de 1883, fugiu da companhia de seus tutores, que residiam na cidade de Ouro Preto. Meses depois da fuga, Antero conheceu o senhor José Pires Gomes de Queiroz, residente na freguesia da Barra Longa, termo de Mariana. Buscando resolver a situação de Antero, Queiroz procurou a justiça afirmando que

há seis meses mais ou menos, achando-se arranchado na propriedade de dona Francisca de Mesquita, ali apareceu o

27 Arquivo da Casa Setecentista de Mariana, I Ofício, códice 389, auto 8.498. 


\begin{abstract}
menor de nome Antero, coberto de andrajos pedindo-lhe o que comer. O suplicante indagando dele donde era e quem eram seus pais, respondeu-lhe ser de Ouro Preto e que seus pais eram falecidos, vivendo em companhia de uma família que o maltratava a ponto de achar-se fugitivo dela. ${ }^{28}$
\end{abstract}

O suplicante convidou-o para morar em sua companhia, o que Antero aceitou com a condição de jamais ser conduzido a Ouro Preto, para evitar encontrar com as pessoas em cujo poder se achava. Depois de informado que praticara um bem, o suplicante conduziu consigo o referido menor e entregou aos cuidados de sua família para receber a instrução e aprender o ofício de sapateiro, ministrando-lhe alimento e vestuário.

Tentando traçar semelhanças entre os exemplos de tutela supracitados, podemos afirmar que, ao menos nas declarações, a justificativa dos candidatos a tutores de menores pobres era cumprir com seus deveres sociais, pois se tratava, de acordo com os tutores, de menores desprovidos de toda e qualquer condição de sobrevivência, muitas vezes sem ter nem ao menos uma ligação parental, precisando urgentemente de cuidados. Os tutores comprometiam-se a garantir aos menores casa, alimentação e vestimenta, além de instruí-los nas primeiras letras, na religião e na aprendizagem de algum ofício para o qual tivessem inclinação, guiando-os assim para o futuro. Os menores, quando aparentados, viviam em ambiente degradante, junto a "homens e mulheres cheios de vícios", com enormes prejuízos à criação de uma criança. Em muitas situações, a criança já vivia no domicílio do candidato a tutor e, ao lado do dever social, estava a justificativa relacionada ao coração, ao sentimento filial que a família tutora nutria pelas crianças. $\mathrm{Na}$ verdade, tratava-se de uma fórmula pouco onerosa e bastante eficiente de obter trabalhadores que atuariam nos serviços domésticos e na lida das roças dos domicílios tutores.

A historiografia referente ao assunto corrobora a hipótese de busca de trabalhadores quando observa que a maioria dos tutelados era do

28 Arquivo da Casa Setecentista de Mariana, I Ofício, códice 410, auto 8.961. 
sexo masculino ${ }^{29}$ e estava na faixa dos 9 aos $21 \operatorname{anos}^{30}$. Apesar de tratar de um pequeno número de crianças, em Mariana computamos, entre os menores tutelados, a presença do dobro de meninos em relação às meninas. Vimos também que as crianças requeridas para tutela já estavam em idade de começar a aprender algum ofício. A preferência pelos meninos maiores, já criados, sugere que os tutores buscavam de fato, pelo meio da tutela, garantir trabalhadores. Alessandra David, ao analisar as ações de tutela para Franca na segunda metade do século XIX, chama a atenção para o tipo de economia vigente na localidade, vinculada ao setor agropastoril, e conclui que o trabalho pesado da agricultura e da criação de animais foi o que determinou a preferência dos tutores por menores do sexo masculino ${ }^{31}$. Levando-se em conta que, para os exploradores da mão-de-obra infantil, o que interessava era a produtividade, este perfil é bastante sugestivo, sobretudo para uma localidade que centrava sua economia nas atividades agrícolas e de criação de animais. Contudo, isso não elimina a participação de meninas (presentes, em especial, nas atividades domésticas e de tecelagem) e de crianças com idade inferior a 10 anos, que poderiam ser inseridas nas mais diversas atividades: "procurar gravetos para acender fogo, varrer quintais, lavar louça, capinar, cuidar de outras crianças, lavar roupas, etc." ${ }^{32}$

A tutela acabou transformando-se em mecanismo de constituição de mão-de-obra. A legislação abolicionista da segunda metade do século XIX, especialmente após 1871 , pode ter incentivado a prática da tutela.

29 Alessandra David, detendo-se na análise da localidade de Franca do período 1850-1888 encontra nada menos que 74\% dos tutelados pertencendo ao sexo masculino (DAVID, 1997, p. 11). Arethuza Helena Zero afirma que $61 \%$ das crianças dos processos judiciais de tutela para a cidade de Rio Claro do período 1871-1888 eram do sexo masculino, fato que, segundo a autora, poderia estar relacionado com a expectativa dos tutores com o trabalho desses jovens, que, em geral, relacionava-se ao setor agrícola preponderante na cidade e época em questão (ZERO, 2004, p. 6).

30 Os registros de tutela, trabalhados por Alaniz para as cidades de Campinas e Itu, revelaram que a maioria dos menores tutelados, $67,58 \%$, estava na faixa etária considerada mais produtiva, isto é, dos 9 aos 21 anos, sendo que, na maioria dos processos onde crianças entre 0 e 8 anos apareceram, estas estavam acompanhadas de irmãos mais velhos (ALANIZ, 1997, p. 56). Para Rio Claro, as 140 crianças dos processos tutelares coletados por Zero estavam, segundo a faixa etária, divididas da seguinte forma: menores na faixa etária dos 0 aos 2 anos correspondiam a apenas 3\%; os que tinham entre 9 e 12 anos, $21 \%$; e aqueles com faixa etária variando entre 13 e 21 anos, $19 \%$ (ZERO, 2004, p. 6).

31 DAVID, 1997, p. 111.

32 AZEVEDO, 1995, p. 37. 
Dividindo os 27 processos em períodos, temos o seguinte resultado: para o intervalo 1860-1871, coletamos apenas um processo; para o período 18711887 , foram seis os processos; a mesma quantidade foi encontrada apenas para o ano de 1888; e, após 1888, temos 14 processos. Esse resultado sugere duas explicações: 1) ainda não achamos documentos pertinentes ao período referente à desarticulação do sistema escravista (1850-1887), e 2) a tutela regulamentaria a "posse" da criança perdida com a abolição. Após a lei de 13 de maio de 1888, os pedidos de tutela foram intensificados com o objetivo de substituir, ao menos parcialmente, os escravos dos domicílios pelo serviço dos menores desamparados ${ }^{33}$.

É preciso lembrar que os registros de tutela abrangem apenas uma parcela das crianças inseridas em domicílios alheios aos de suas origens. Boa parte deles, ademais, apenas legitimava uma situação que já existia, ou seja, os menores já moravam com tutores, mas não oficialmente. Por meio dos processos-crime, algumas dessas crianças puderam ser conhecidas. Foram de nosso interesse aqueles processos que envolveram crianças livres e pobres com até 14 anos no período 1850-1900 e estão conservados no Arquivo da Casa Setecentista de Mariana.

Tais processos narram o contexto dos crimes, suas causas e as características dos envolvidos, revelando-nos, ao longo de suas páginas, informações que ultrapassam a situação do crime, fornecendo-nos dados que confirmam a relação criança/trabalho existente em muitos domicílios marianenses na segunda metade do século XIX. Coletamos 70 processoscrime que narraram histórias envolvendo 103 crianças. Dividindo no tempo, temos 18 processos referentes aos anos 1850, 10 referentes aos anos 1860 , 10 para o decênio de 1870,16 para os anos 1880 e 16 para a última década.

33 A pesquisa de Alaniz corrobora a hipótese de que, especialmente após a abolição, a tutela representou um meio de assegurar a "posse" das crianças pobres - muitas vezes, descendentes da escravidão - com a finalidade de servirem como trabalhadores aos tutores. Investigando os casos de tutela ocorridos nas cidades de Campinas e Itu, a autora constata que, somente no ano de 1888, 72 ingênuos foram tutelados. "Isso representa $60 \%$ de todos os ingênuos tutelados durante o período estudado, isto é, entre 1871 e 1895" (ALANIZ, 1997, p. 58-59). Maria Aparecida Papali coletou 330 ações de tutela referentes a Taubaté no período de 1871 a 1895 e constatou que grande quantidade dessa documentação foi emitida após a abolição. Dos 427 menores tutelados, 366 foram tutelados entre os anos de 1888 e 1895, o que representa $85,7 \%$ do total (PAPALI, 2003, p. 131). 
TABELA 4 - Crianças nos processos crimes segundo sexo e idade - Mariana, segunda metade do século XIX

\begin{tabular}{|l|c|c|c|}
\hline \multicolumn{1}{|c|}{ Faixa etária } & Meninos & Meninas & Total \\
\hline 0-4 anos & 3 & 2 & 5 \\
\hline 5-9 anos & -- & 4 & 4 \\
\hline 10-14 anos & 47 & 19 & 66 \\
\hline Sem informação & 13 & 15 & 28 \\
\hline Total & $\mathbf{6 3}$ & $\mathbf{4 0}$ & $\mathbf{1 0 3}$ \\
\hline
\end{tabular}

A divisão por sexo e faixa etária revela o predomínio dos meninos com idade entre 10 e 14 anos nos processos de natureza criminal (Tabela 4). Das 103 crianças, 63 eram meninos - o que correspondia a 61,2\% do total da amostragem -, sendo que, destes, 47 estavam na última faixa etária. Entre as meninas, também era a faixa 10-14 anos a que concentrava a maioria das crianças presentes nos processos. As crianças que não tiveram as idades informadas foram consideradas como menores de 15 anos pelas expressões de tenra idade, menino/menina, moleque/moleca.

TABELA 5 - Crianças nos processos crimes segundo ocupações - Mariana, segunda metade do século XIX

\begin{tabular}{|l|c|c|c|}
\hline \multicolumn{1}{|c|}{ Situação } & Meninos & Meninas & Total \\
\hline Com ocupação descrita & 43 & 15 & 58 \\
\hline Sem informação & 20 & 25 & 45 \\
\hline Total & $\mathbf{6 3}$ & $\mathbf{4 0}$ & $\mathbf{1 0 3}$ \\
\hline
\end{tabular}

Algum tipo de ocupação foi descrito para 58 crianças da amostragem. Esse número equivale a 56,3\% do total de crianças analisado. Separando meninos e meninas, observamos que foi mais comum a descrição ocupacional para os meninos: do total das crianças com ocupação mencionada, 43 eram do sexo masculino ( $74,1 \%$ do total) e 15 do sexo feminino (25,9\% do total). Todas as crianças que tiveram ocupação descrita eram maiores de 10 anos; entretanto, pequenas tarefas associadas ao cotidiano 
da família poderiam ser desenvolvidas independentemente da idade. A formação para o trabalho das crianças oriundas de famílias pobres parece ocorrer desde os primeiros anos de vida, sendo as crianças responsáveis por tarefas correspondentes a sua força física. O processo-crime que narra o assassinato do menino Domingos, de três para quatro anos, exemplifica essa idéia ${ }^{34}$. O crime aconteceu no ano de 1858 e foi denunciado pelo pai da vítima, Francisco Antônio. Pelas testemunhas, foi dito que o autor do homicídio era João do Nascimento, de vinte e tantos anos, vizinho da vítima. Quando do ocorrido, as testemunhas afirmaram que o menino sofrera agressões físicas provocadas por um cabresto que acarretaram sua morte. A quarta testemunha, João Inácio Dias, disse

\footnotetext{
que sabe por ver que João do Nascimento é quem deu no dito menino com um cabresto e ele testemunha pediu a ele que não desse mais no menino e este o respondeu dizendo-lhe que fosse governar sua casa e que estas pancadas foram dadas de noite, motivo por que ele réu descascou uma espiga de milho e deu ao menino para debulhar e como o menino estava com uma queimadura na palma de uma mão não podendo debulhar o milho pegou ele réu as pancadas com $\mathrm{ele}^{35}$.
}

Voltando à Tabela 5, vimos que as ocupações das meninas foram menos descritas. Isso não quer dizer que estavam menos propensas à realização de tarefas diárias. Examinando os processos nos quais as meninas estavam envolvidas, percebemos que a maioria dos crimes envolvendo-as acontecia em ambiente particular, normalmente onde residiam e/ou trabalhavam as vítimas ${ }^{36}$. Nestes casos, predominavam nos autos as relações das meninas com o domicílio (se eram filhas, agregadas, afilhadas, etc.), ficando

34 Arquivo da Casa Setecentista de Mariana, II Ofício, códice 209, auto 5.230.

35 Arquivo da Casa Setecentista de Mariana, II Ofício, códice 209, auto 5.230, p. 7 e 7v.

36 Das 40 meninas amostradas, 35 apareceram nos processos como vítimas, quatro como testemunhas e apenas uma como ré. Os processos relacionados às meninas tinham como mote principal os crimes sexuais: seduções, defloramentos, raptos com fins libidinosos. Por ora, não nos aprofundaremos na questão, que comporá parte de outro capítulo. 
omitidas as tarefas do dia-a-dia que deveriam executar. Maria Madalena Augusta do Espírito Santo, de 14 anos, era órfã e vivia sob a proteção da família do dentista Felicíssimo de Castro Guimarães quando, no ano de 1889, denunciou Cassiano Marcelino, empregado do dito Felicíssimo, por sedução, tendo como resultado o estado de prenhez em que a mesma se encon$\operatorname{trava}^{37}$. Em testemunho, o senhor Felicíssimo disse que a menina havia um ano e tanto mais chegou em sua casa conduzida por dona Carolina Augusta de Figueiredo, que pediu para sua senhora para tomar conta da menina. Por dona Carolina, foi dito que a menina antes de ir para seu poder tinha morado em residência do tenente Amélio Augusto de Figueiredo - pela semelhança dos nomes, provavelmente irmão ou filho da senhora Carolina - de onde fugira alta noite, tendo como motivo o espancamento que sofreu na casa do tenente. Outras informações sobre a vida da jovem Maria Madalena não nos foi possível conhecer, mas o fato de ser órfã miserável fez com que seus últimos anos fossem uma constante circulação entre residências. As causas que levaram os referidos senhores a abrigar Maria Madalena estão ligadas a sua condição de pobre, órfã e menor carecendo de proteção. Mas, em troca da proteção - amparo moral, subsistência física e educação -, as meninas deveriam prestar algum tipo de serviço aos domicílios protetores. Na maior parte dos processos, os deveres das protegidas não estão claros, mas não constituía a caridade pura e simples o único fundamento do funcionamento do sistema de acolhida de meninas pobres pelos senhores marianenses.

O processo-crime datado do ano de 1890 denuncia maus-tratos em Delmina Pereira Dias e exemplifica o que nomeamos acima como troca. A menina residia na casa do pedreiro Galdino Gonçalves da Silva Paixão com o consentimento da mãe, que entregou sua filha para que Galdino e esposa, Maria José de Jesus, tomassem conta. As testemunhas do processo mencionam que quando Delmina chegou à casa de Galdino estava em estado miserável, coberta de sarnas, bichos e piolhos. Quanto ao tratamento recebido pela menina, as testemunhas não são unânimes. Algumas afirmaram que Galdino e senhora sempre trataram Delmina com todo o cuidado e carinho

37 Arquivo da Casa Setecentista de Mariana, I Ofício, códice 346, auto 7.636 
como de pais para filha andando sempre limpa e alimentada. Entretanto, a maioria afirmou que a mulher do acusado, por correção, costumava bater e castigar a menina, mas de modo que nunca a maltratou.

A testemunha Carolina Margarida de Jesus

(...) respondeu que sabe de consciência própria por ter visto a mulher do acusado, muitos dias antes, estando a dita menina rachando lenha, ela testemunha viu a própria mulher do acusado dar-lhe uma bordoada com um cabo de vassoura nas costas da dita menina ${ }^{38}$.

O motivo da agressão teria decorrido do fato de a menina ter "se demorado muito em rachar um pau de lenha" ${ }^{39}$. A troca existente entre protetores e protegidos fica evidenciada quando reconhecemos que Galdino e esposa cuidaram da higiene da menina Delmina, que chegou em sua residência coberta de sarnas, bichos e piolhos, além de alimentá-la e vesti-la. Em pagamento, a menina executaria tarefas ligadas ao cotidiano da família de Galdino. Em depoimento, Delmina disse que tinha como profissão tomar conta de crianças e que

\footnotetext{
era muito castigada em casa dos denunciados, tendo sido ferida na cabeça com o cabo de uma vassoura, [além do] ferimento nos braços que era em consequiência de chicotadas e que tinha diversos ferimentos pelo corpo de castigos reiterados e que quanto a subsistência era bem tratada, recebendo boa alimentação ${ }^{40}$.
}

Castigos com cunho "educativo" eram considerados normais. Mesmo nos casos de excesso, como ocorreu com Delmina - o auto de corpo de delito constatou fratura no rádio do antebraço direito, além da região renal e também uma contusão sobre a região do osso sacro esquerdo -, as testemunhas afirmaram que aconteciam por correção e não por maldade.

38 Arquivo da Casa Setecentista de Mariana, II Ofício, códice 199, auto 4.973, p. 13. 39 Arquivo da Casa Setecentista de Mariana, II Ofício, códice 199, auto 4.973, p. 28v

40 Arquivo da Casa Setecentista de Mariana, II Ofício, códice 199, auto 4.973, p. 39v. 
Uma das testemunhas chegou a declarar que os castigos eram próprios de um pai a fim de apenas corrigir. Sendo assim, conhecemos a violência cometida contra Delmina por denúncia de sua mãe, Carolina Maria dos Reis que

\begin{abstract}
indo a casa dos denunciados buscar a sua filha de nome Delmina Pereira Dias, visto ter-se de mudar para o Cuiabá perto de Caeté, encontrou-a com o braço fraturado e a cabeça quebrada e escorrendo sangue, e o osso da virilha quebrado, os calcanhares machucados, dizendo a menina que esses ferimentos tinham sido feitos pelos denunciados. (...). Respondeu mais que a ofendida esteve um mês e quinze dias no hospital de Ouro Preto tratando de todos esses ferimentos, estando hoje completamente restabelecida ${ }^{41}$.
\end{abstract}

Possivelmente, se a mãe de Delmina não tomasse conhecimento das agressões sofridas pela filha, os castigos continuariam e o fim dessa história seria outro.

A divisão das ocupações segundo o gênero das crianças pode ser observada pela Tabela 6. Para os meninos, as ocupações atribuídas foram de roceiro/lavrador, candeeiro, carreiro, mineiro, pedreiro, sapateiro, soleiro, jornaleiro, estudante. Para as meninas, as ocupações estavam ligadas aos serviços domésticos: cozinheira, costureira (houve também um menino com a ocupação de cozinheiro), tomar conta de crianças, lavadeira. Algumas vezes, as tarefas não eram descritas, mas a condição de trabalhador aparecia. Este foi o caso do menino Raimundo de Tal, camarada de Martinho Alexandre de Macedo ${ }^{42}$ e de Francisco de Sales, que estava empregado na casa de Francisco José de Oliveira ${ }^{43}$.

Muitas das crianças ainda estavam na condição de aprendizes de algum ofício. Era na condição de aprendizes de alfaiate que estavam Lucas, 12 anos, e Júlio de Paula Dias Bicalho, 11 anos, quando testemunharam a tesourada dada pelo próprio mestre de alfaiataria no aprendiz Francisco

\footnotetext{
41 Arquivo da Casa Setecentista de Mariana, II Ofício, códice 199, auto 4.973, p. 37

42 Arquivo da Casa Setecentista de Mariana, II Ofício, códice 208, auto 5.196.

43 Arquivo da Casa Setecentista de Mariana, I Ofício, códice 364, auto 8.018.
} 
TABELA 6 - Ocupações descritas nos processos segundo gênero - Mariana, segunda metade do século XIX

\begin{tabular}{|c|c|c|c|}
\hline Situação & Meninos & Meninas & Total \\
\hline Ligadas ao ofício de roceiro/lavrador & 14 & - & 14 \\
\hline Candeeiro & 2 & - & 2 \\
\hline Carreiro & 2 & - & 2 \\
\hline Mineiro & 2 & - & 2 \\
\hline Pedreiro/aprendiz de pedreiro & 2 & - & 2 \\
\hline Sapateiro/aprendiz de sapateiro & 1 & - & 1 \\
\hline Alfaiate/aprendiz de alfaiate & 4 & - & 4 \\
\hline Aprendiz de carpinteiro & 1 & - & 1 \\
\hline Soleiro/aprendiz de soleiro & 1 & - & 1 \\
\hline Cozinheiro(a) & 1 & 2 & 3 \\
\hline Costureira/aprendiz de costureira & - & 4 & 4 \\
\hline Tarefas domésticas & - & 3 & 3 \\
\hline Tomar conta de crianças & - & 1 & 1 \\
\hline Lavadeira & - & 2 & 2 \\
\hline Agenciadora & - & 1 & 1 \\
\hline Empregado/camarada/jornaleiro/agregado & 10 & - & 10 \\
\hline Que a criança deve sujeitar a seus pais & 1 & 2 & 3 \\
\hline Estudante & 2 & - & 2 \\
\hline Total & 43 & 14 & 58 \\
\hline
\end{tabular}

Agostinho Xavier, de $14 \operatorname{anos}^{44}$. Os depoimentos sugerem que o ocorrido na oficina não passou de um acidente de trabalho, pois, segundo as testemunhas, o ferimento foi ocasional por estar o senhor Antônio Aniceto da Silva com a tesoura a cortar uma obra quando a esbarrou no braço de Francisco, que perto do mesmo Aniceto trabalhava.

44 Arquivo da Casa Setecentista de Mariana, II Ofício, códice 235, auto 5.870. 
TABELA 7 - Vínculo familiar entre as crianças - Mariana, segunda metade do século XIX

\begin{tabular}{|l|c|c|c|}
\hline \multicolumn{1}{|c|}{ Vínculo familiar } & Meninos & Meninas & Total \\
\hline Pai e mãe & 8 & 12 & 20 \\
\hline Órfão de pai & 3 & 2 & 5 \\
\hline Órfão de mãe & 3 & 3 & 6 \\
\hline Mãe & 8 & 11 & 19 \\
\hline Pai & 9 & 3 & 12 \\
\hline Órfão & 3 & 3 & 6 \\
\hline S/I & 29 & 6 & 35 \\
\hline Total & $\mathbf{6 3}$ & $\mathbf{4 0}$ & $\mathbf{1 0 3}$ \\
\hline
\end{tabular}

S/I - Sem informação

Apesar de as narrações dos fatos que deram origem aos processos nos revelarem que a maioria dos crimes ocorrera fora do ambiente familiar, as crianças amostradas a partir dos processos-crime foram descritas com seus vínculos ascendentes. Das 103 crianças, apenas seis eram órfãs de pai e mãe. Para 62 meninos e meninas, pai e/ou mãe foram revelados pelos processos. Desses, 31 tiveram a filiação paterna e materna descrita (sendo 11 órfãos de um dos progenitores). A descrição apenas da filiação materna aconteceu em 19 casos e, em outros 12, apenas o pai constou nos autos. Para 35 crianças, não temos informações sobre seus progenitores.

TABELA 8 - Domicílio das crianças - Mariana, segunda metade do século XIX

\begin{tabular}{|l|c|c|c|}
\hline \multicolumn{1}{|c|}{ Domicílio } & Meninos & Meninas & Total \\
\hline Residiam com família & 24 & 19 & $\mathbf{4 3}$ \\
\hline Não residiam com família & 11 & 14 & $\mathbf{2 5}$ \\
\hline Sem informação & 28 & 7 & $\mathbf{3 5}$ \\
\hline Total & $\mathbf{6 3}$ & $\mathbf{4 0}$ & $\mathbf{1 0 3}$ \\
\hline
\end{tabular}

S/I - Sem informação 
Das 62 crianças com descrição de pai e/ou mãe, 43 residiam com ao menos um de seus progenitores. Para essas crianças, as ocupações diárias poderiam estar ligadas às atividades da própria família ou mesmo extrapolar o espaço familiar, sendo a criança empregada em domicílios vizinhos. O processo-crime aberto em conseqüência das agressões físicas sofridas pelo menor Modesto de Souza ilustra o primeiro caso ${ }^{45}$. Modesto tomava conta da venda de seu pai, Francisco Camargo, que ficava na parte da frente da casa da família, quando na noite do dia 17 de julho de 1873 foi agredido por um freguês de nome João André. A ofensa decorreu-se depois de João André pedir um pouco de aguardente, ao que Modesto respondeu que não podia atendê-lo naquele momento por estar carregando seu irmão. A frequiência com que Modesto atuava à frente da venda de seu pai não é possível conhecer, mas o fato de o menino também estar, no momento da agressão, pajeando seu irmão de colo sugere que, talvez, sua contribuição na vida familiar não estivesse fechada a uma única atividade e sim a uma série de tarefas desenvolvidas ao longo do dia.

Antônio Ferreira, de 14 anos, testemunha de crime de seqüestro, sintetizou com poucas palavras o que pretendemos sugerir. Quando da sua apresentação para realização de seu depoimento, perguntaram-lhe sobre sua profissão, ao que respondeu a "que a criança deve sujeitar a seus pais" ${ }^{46}$. Nenhum outro detalhe foi dado, mas podemos pensar em pequenas tarefas do cotidiano familiar como, por exemplo, buscar água, apanhar lenha, tomar conta dos irmãos menores, serviços de recado, colheita, etc. A menina Ricardina de Oliveira Quites, também com 14 anos, vítima de rapto, quando perguntada sobre sua profissão, disse que estava "sujeita aos trabalhos domésticos da casa de sua mãe"47.

O jovem Henrique Diogo dos Santos, indiciado no ano de 1895 por ferimentos à faca em seu padrasto, tinha entre 12 e 13 anos de idade e também residia com sua mãe, Felícia da Conceição, além de um irmão e o padrasto Ricardo do Carmo. Mas, ao contrário dos casos acima mencionados, saíra dos limites de sua residência, indo ocupar-se como mineiro na

45 Arquivo da Casa Setecentista de Mariana, II Ofício, códice 182, auto 4.538.

46 Arquivo da Casa Setecentista de Mariana, II Ofício, códice 209, auto 5.238 .

47 Arquivo da Casa Setecentista de Mariana, I Ofício, processos avulsos, códice 14, auto 279. 
companhia inglesa instalada no Morro de Santana em Mariana ${ }^{48}$. O cotidiano da menina Amélia, 14 anos, também extrapolava a própria casa. Em 1888, seu pai denunciou que a filha havia sido vítima de defloramento e que o autor seria Honório Firmino Carneiro Belfort. Amélia era cozinheira no domicílio do réu, onde também aprendia as primeiras letras com a mulher do mesmo. Uma das testemunhas afirmou que a menina havia sido alugada pelo próprio pai para servir à família de Honório e que diariamente "vinha só da casa de seus pais para a casa do acusado, e que [também] ia ao mato lenhar em companhia apenas das suas irmãs, sendo uma mais velha e uma mais moça"49. O pai de Amélia foi descrito como extremamente pobre, necessitando da ajuda das filhas para a manutenção da família. Muito pobre também era a família de José Inácio, vítima de assassinato em 1869, de 14 anos, que residia com a mãe viúva e o irmão. Pela própria mãe, foi dito em depoimento que a família "vive de seu trabalho juntamente com o de seus filhos", que eram ocupados com tropa ${ }^{50}$.

Os encargos ligados ao trabalho faziam com que alguns menores fossem obrigados a ausentar-se temporariamente da família. Era essa a situação vivida por Bernardo, descrito como jornaleiro e lavrador, natural de Mariana, mas que vivia em Ouro Preto quando lá trabalhava ${ }^{51}$. José Antônio, crioulo, forro, de 14 anos de idade, que vivia de deslocar tropa, era natural do Bom Retiro, mas residia no Cunha em casa de José Martins, onde trabalhava. Em julho de 1853, fora roçar na fazenda do Cunha a pedido do proprietário João Martins Vieira (primo de José Martins) quando se envolveu num conflito com José Cleto de Campos, agregado na fazenda do $\mathrm{Cu}$ nha, o que resultou em ferimentos à faca no braço do primeiro e na morte do segundo.

José Antônio trabalhou vários dias na fazenda do Cunha. No dia do crime, José Cleto foi quem iniciou a briga, partindo para cima de José Antônio com uma foicinha. Respondendo ao ataque, José Antônio, que

48 Arquivo da Casa Setecentista de Mariana, I Ofício, processos avulsos, códice 25, auto [não

49 Arquivo da Casa Setecentista de Mariana, I Ofício, códice 360, auto 7.938, p. 41.

50 Arquivo da Casa Setecentista de Mariana, II Ofício, códice 181, auto 4.504, p. 41.

51 Arquivo da Casa Setecentista de Mariana, I Ofício, códice 364, auto 8.018. Em um momento de lazer, caçando pombos com amigos, Bernardo acabou acertando fatalmente um tiro de espingarda em um de seus companheiros, o menino José Eduardo de Oliveira. 
portava uma faca, atingiu mortalmente seu agressor. Entre os dois envolvidos havia uma antiga rixa - por causa de uma crioula, também residente no Cunha -, que foi intensificada quando Cassiano Martins, herdeiro da fazenda do Cunha, convidou José Antônio para sair com sua tropa. No interrogatório, o réu afirmou que
vindo de casa de seu amo, José Martins Vieira, à fazenda do Cunha com o fim de tomar uma foice para trabalhar ali mesmo na fazenda e encontrando logo com o escravo da casa, Pedro, que com ele réu dirigiu-se ao quarto para dar-lhe a dita foice, estava nesta ocasião no quarto de João Moleque que fica imediato ao do dito José Cleto que apenas avistou ele réu disse "ali vem o diabo do negro e agora vou o matar" e saindo com uma foice procurou com toda instância ferir ele réu, o que não conseguiu logo porque o escravo Pedro bastantes diligências fez no meio deles ambos para impedir o sucesso, mas que vendo-se o dito Pedro ameaçado por José Cleto separou-se e o réu já sem recursos teve de lançar mão da faca para defender sua vida. ${ }^{52}$

Não conseguimos aferir as causas que levaram José Antônio a viver longe da família com o propósito de trabalhar, mas as características do menor - crioulo, filho de Claudina Maria, possivelmente sem pai, não sabia nem ler nem escrever - qualificam-no com o perfil do menor carente que mergulhava no trabalho desde tenra idade devido à necessidade de sobrevivência.

A omissão da filiação das crianças ocorrida em vários processos sugere-nos que, para muitas crianças, o afastamento da família original não seria temporário. Sem nenhuma menção de parentesco estava José Libânio, que aparece num processo-crime como vítima de agressão. O menino encontrava-se em um rancho de tropa, onde servia de cozinheiro para os carpinteiros que lá trabalhavam, quando foi ofendido no rosto pelo americano James Johnsons, também trabalhador no mesmo rancho. De acordo com as testemunhas, o acusado chegou ao rancho por volta de uma hora da tarde 
do dia 9 de outubro de 1887, mandando o menor abotoar o colarinho de sua camisa; recusando-se José Libânio a fazer o que lhe fora mandado, seguiu para dentro do rancho para providenciar o jantar. No mesmo momento, recebeu uma bordoada do acusado que o deixou desacordado. As testemunhas relataram que o acusado já tentara agredir o menor outras vezes, o que ainda não havia acontecido devido às intervenções dos homens presentes. $\mathrm{O}$ exame de corpo de delito concluiu que, apesar de não ser mortal, a agressão provocou grave incômodo de saúde no ofendido José Libânio, que o inabilitou para o serviço por mais de 30 dias. Tal prejuízo foi avaliado em $50 \mathrm{mil}$ réis ${ }^{53}$.

\section{Considerações finais}

Buscamos, neste artigo, levantar algumas questões que relacionam criança e trabalho numa localidade envolvida economicamente com atividades ligadas à subsistência no período conturbado da segunda metade do século XIX, quando o país estava envolto na discussão sobre o fim do sistema escravista e sobre as formas de trabalho que o substituiriam. Entre as propostas, estava aquela defendida pelos proprietários mineiros que idealizava a utilização da mão-de-obra nacional: livres pobres, libertos, ingênuos. Nesse sentido, as crianças poderiam ser vistas com bastante interesse, pois poderiam, desde cedo, ser educadas para o trabalho.

Perceber o interesse dos cidadãos marianenses pela criança livre e sem recursos foi nosso objetivo principal. Pelo recenseamento da população marianense, contido no censo nacional de 1872, estimamos que cerca de 24,2\% (sendo $20,7 \%$ na condição de livres e 3,5\% na condição de escravos) dos habitantes de Mariana tinham até 15 anos. A condição de livres das crianças não era garantia de uma vida longe do trabalho; calcula-se que a grande maioria vivia em condições precárias e sua força de trabalho era essencial à produção familiar ou explorada por tutores/patrões.

53 Arquivo da Casa Setecentista de Mariana, II Ofício, códice 201, auto 5.021, p. 4v. 
Propomo-nos a identificar as causas pelas quais ocorria a precoce entrada no mundo do trabalho e verificamos, assim, que a orfandade e a pobreza eram, no mais das vezes, motivos bastantes para a criança ser alijada de sua infância. $\mathrm{O}$ encontro com o trabalho poderia acontecer no próprio ambiente familiar ou em propriedades alheias. Neste último caso, os domicílios que acolhiam menores oriundos da orfandade e da pobreza encontravam na instituição da tutela o artifício legal que garantiria a guarda até que os menores completassem 21 anos. A tutelagem funcionava, em muitos casos, como um sistema de troca: o tutor fornecia proteção, subsistência e educação (quase sempre associada à aprendizagem de uma profissão) e o papel do tutelado estava associado à prestação de serviços.

Os processos de tutela coletados para Mariana sugerem a preferência dos tutores pelos meninos em idades superiores aos seis anos. Essas características teriam relações com a produtividade. Numa localidade envolvida economicamente com roças e criação de animais, meninos seriam mais úteis. Entretanto, as meninas não estavam ausentes nem tampouco eram descartadas como auxílio, em especial, nas atividades domésticas e de tecelagem.

Os registros de tutela abrangem apenas uma pequena parcela das crianças inseridas em domicílios alheios aos de origem. Boa parte deles apenas legitimava uma situação que já existia, ou seja, os menores já moravam com seus tutores, mas não oficialmente. Os processos-crime coletados narram histórias de crianças que residiam fora do núcleo familiar sem a legalização por meio da tutela ou que coabitavam com seus pais, mas deslocavam-se para outros domicílios em decorrência da necessidade de buscar a sobrevivência por intermédio do trabalho.

\section{Referências}

ALANIZ, Anna Gicelle Garcia. Ingênuos e libertos: estratégias de sobrevivência familiar em época de transição 1871-1895. Campinas: Unicamp, 1997.

AZEVEDO, Gislaine C. Sebastianas e Geovannis: o universo do menor nos processos dos Juízos de Órfãos da cidade de São Paulo (1871-1917). Dissertação (Mestrado em História) - Pontifícia Universidade Católica de São Paulo, 1995. 
BASSANEZI, Maria Sílvia C.; SCOTT, Ana Sílvia V. Criança e jovem oriundi na terra do café, final do século XIX e início do XX. (Comunicação apresentada na I Jornada de História da família - CEDHAL/USP, 2003, 19 p.)

DAVID, Alessandra. Tutores e tutelados: a infância desvalida em Franca (18501888). Dissertação (Mestrado em História) - Faculdade de História, Direito e Serviço Social da Universidade Estadual Paulista, 1997.

GEBARA, Ademir. O mercado de trabalho livre no Brasil (1871-1888). São Paulo: Brasiliense, 1986.

GRAHAM, Sandra Lauderdale. Proteção e obediência: criadas e seus patrões no Rio de Janeiro (1860-1910). São Paulo: Companhia das Letras, 1992.

KOWARICK, Lúcio. Trabalho e vadiagem: a origem do trabalho livre no Brasil. São Paulo: Brasiliense, 1987.

LANNA, Ana Lúcia. A transformação do trabalho. 2. ed. Campinas: Unicamp, 1989.

MARCÍlIO, Maria Luiza. Relatório final do projeto "História Demográfica da Infância Brasileira: quatro séculos de marginalização". Julho de 1992 (mimeografado).

PAPALI, Maria Aparecida. Escravos, libertos e órfãos: a construção da liberdade em Taubaté (1871-1895). São Paulo: Anablume, Fapesp, 2003.

PINHEIRO, Luciana de Araújo. A civilização do Brasil através da infância: propostas e ações voltadas à criança pobre nos finais do Império (1879-1889). Dissertação (Mestrado em História) - Universidade Federal Fluminense, 2003.

TEIXEIRA, Heloísa M. A não-infância: crianças como mão-de-obra compulsória em Mariana (1850/1900). XIII ENCONTRO NACIONAL DE ESTUDOS POPULACIONAIS, 13., 2002, Ouro Preto. Anais... Ouro Preto: Abep, 2002. 1 CD-ROM.

ZERO, Arethuza Helena. Ingênuos, libertos, órfãos e a Lei do Ventre Livre. In: CONGRESSO BRASILEIRO DE HISTÓRIA ECONÔMICA, 5., 2003, Caxambu. Anais... Caxambu: ABPHE, 2003.

Questão da tutoria e a Lei do Ventre Livre: conflito e mortalidade nos últimos anos da escravidão em Rio Claro (1871-1888). ENCONTRO DA PÓSGRADUAÇÃO EM HISTÓRIA ECONÔMICA, 2., 2004, Niterói. Anais... Niterói: ABPHE, 2004. 